\title{
O sujeito no feminismo: revisitando os debates ${ }^{*}$
}

\author{
Claudia de Lima Costa**
}

\begin{abstract}
Resumo
No presente artigo, examino a condição disciplinar do sujeito no feminismo, sua identidade ambivalente e sua capacidade de agenciamento à luz das discussões sobre identidade, diferença, lugar e enunciação articulados pelas teorias feministas pósestruturalistas. Tendo em vista que não podemos abordar questões sobre o(s) sujeito(s) e sua(s) identidade(s) sem examinarmos os vetores constitutivos dos mesmos, exploro como as teorias feministas têm sido capazes de oferecer definições alternativas (de uma maior positividade) do sujeito $e$ da identidade que, mesmo que se apoiando na inevitabilidade epistemológica da desconstrução desses, resistem ao perigo de esvaziá-los de qualquer materialidade.
\end{abstract}

Palavras-chave: Identidade, Diferença, Teorias Feministas, PósEstruturalismo, Lugar de Enunciação.

\footnotetext{
* Recebido para publicação em março de 2002.

*** Professora adjunta de Teoria Literária e Estudos Culturais na Universidade Federal de Santa Catarina e pesquisadora do CNPq.
} 
O sujeito no feminismo

Revisiting the Debates on the Subject in Feminism

\begin{abstract}
In the present article I revisit the disciplinary status of the subject in feminism, its ambivalent identity and its potential for agency in light of the debates on identity, difference, and the notion of place of enunciation articulated by recent poststructuralist feminist theories. Since one cannot broach questions about the subject and its identity without analyzing their constitutive vectors, in this essay I explore how feminist theories have articulated alternative and more positive accounts of the subject and identity which, without abandoning the epistemological inevitability of the subject's deconstruction, nonetheless resist the danger of emptying it of any materiality.
\end{abstract}

Key Words: Identity, Difference, Feminist Theories,

Poststructuralism, Place of Enunciation. 
Claudia de Lima Costa

\section{Aspectos do debate}

Já foi amplamente discutido na literatura que o feminismo nos dias atuais passou a incorporar uma extensa gama de discursos diversificados, resultando em uma grande variedade de feminismos. ${ }^{1}$ Contudo, como argumentei anteriormente, essa heterogeneidade interna não fragmentou nem enfraqueceu a importância política do feminismo, pois ela traz em seu bojo a necessidade de construção de articulações entre as diversificadas posições de sujeito, o que por sua vez compõe a força específica do feminismo diante dos outros movimentos ou discursos sociais. ${ }^{2}$

Já que é exatamente essa articulação que possibilita ao sujeito algum espaço de agenciamento e resistência, o feminismo tem sido eleito por vários teóricos (filiados às tendências pós-estruturalistas mais recentes) como "a prática/discurso contestatório único, ou mesmo suficiente" da teoria social atual. ${ }^{3}$ De acordo com Paul Smith, através da articulação simultânea da heterogeneidade e da singularidade, o feminismo tem sido capaz de "produzir uma oposição coordenada às opressões materiais concretas". Acredito, contudo, que a ironia desse reconhecimento tardio está no fato de que o feminismo alcançou tal estágio não pelo uso de um sujeito construído (de forma exclusiva ou mesmo parcial) por meio da lógica pós-estruturalista da negatividade (lógica a qual esses teóricos se subscrevem). ${ }^{5}$ Ao contrário, o

${ }^{1}$ Este artigo é parte de uma discussão mais ampla sobre os alcances e limites da "experiência" para a teoria feminista em suas várias localizações geopolíticas. Escrito originalmente em inglês, foi aqui traduzido por Liane Schneider.

2 Costa, Claudia de Lima. O tráfico no gênero. Cadernos Pagu (11), Núcleo de Estudos de Gênero - Pagu, Unicamp, 1998, p.127-140.

3 SMITH, Paul. Discerning the Subject. Minneapolis, University of Minnesota Press, 1988, p.154.

4 ID., IB., p.153.

${ }^{5}$ Para os estruturalistas franceses (seguidos pelos seus colegas pósestruturalistas) os fenômenos sociais eram concebidos em termos de estruturas lingüísticas e sociais, de regras, códigos e sistemas, rejeitando assim o 
O sujeito no feminismo

sucesso que Smith (e outros "homens no feminismo") ${ }^{6}$ confere com propriedade à força política do feminismo, a meu ver, devese ao fato de que tal projeto tem sido, por um lado, o de construir positividades para os seus sujeitos com base na materialidade das experiências que as mulheres têm do social, e, por outro, conforme Elspeth Probyn observa, por submeter essas experiências ao escrutínio teórico-crítico. ${ }^{7}$ Contrárias à dissipação do sujeito dentro das estruturas da linguagem e do discurso, tão em voga nos círculos pós-modernos, as feministas têm afirmado que "a outra [mulher] existe em seu próprio lugar, como ela é, independentemente de quaisquer relações específicas". 8

No presente artigo, examino a condição disciplinar do sujeito no feminismo, sua identidade ambivalente $e$ sua capacidade de agenciamento, particularmente em um momento

humanismo que moldara anteriormente as Ciências Humanas e Sociais: "A crítica estruturalista buscou eliminar o conceito do sujeito que havia dominado a tradição filosófica de Descartes a Sartre. O sujeito foi descartado, ou radicalmente descentrado, como sendo um mero efeito da linguagem, da cultura ou do inconsciente, sendo-lhe negado qualquer eficácia causal ou criativa. $\mathrm{O}$ estruturalismo destacou a qualidade derivada da subjetividade e do significado em oposição à primazia dos sistemas simbólicos, do inconsciente e das relações sociais. Nesse modelo, o significado não é a criação de intenções transparentes do sujeito autônomo; o próprio sujeito se constitui pelas suas relações dentro da linguagem, de forma que a subjetividade é percebida como uma construção social e lingüística". (BEST, Steve and KELLnER, Douglas. Postmodern Theory: Critical Interrogations. New York, The Guilford Press, 1991, p.19.) Em outras palavras, apoiando-se na teoria do significado de Saussure - que vê a linguagem como um sistema de diferenças sem termos positivos -, certas variedades do pósestruturalismo defendem que as identidades apenas se instalam através de processos de negação e diferenciação.

6 A expressão "homens no feminismo" faz referência ao título de uma coletânea, intitulada Men In Feminism (JARDINE, Alice and SMITH, Paul. (eds.) New York, Methuen, 1987).

7 Probyn, Elspeth. Sexing the Self: Gendered Positions in Cultural Studies. New York, Routledge, 1993, pp.7-31.

8 Grossberg, Lawrence. Identity and Cultural Studies: Is It All There Is? In: HALL, Stuart and Du GAY, Paul. (eds.) Questions of Cultural Identity. Thousand Oaks, Sage Publications, 1996, p.94 (ênfase no original). 
em que se está recorrendo ao (problemático) princípio da negatividade para impulsionar esse sujeito à ação. Gostaria de argumentar que as condições de possibilidade que autorizam uma política e prática feminista derivam das positividades inerentes à posição paradoxal que seu sujeito ocupa tanto nos discursos/ representações como nas lutas sociais mais amplas. Destacar essas positividades que (in)formam o sujeito feminista, conforme discuto mais adiante, também nos distanciará de uma abordagem exclusivamente lingüística ou textual dos dilemas referentes à subjetividade e à identidade. ${ }^{9}$

\section{Da metafísica negativa à positividade política}

Nos círculos pós-modernos, seguindo uma "lógica feminocêntrica" ${ }^{10}$, certos intelectuais têm freqüentemente utilizado a figura da mulher - como negatividade, ausência $e$ falta - a fim de descentrar a si próprios das certezas das definições logocêntricas de identidade. Discorrendo sobre o lugar que a figura do feminino ocupa nos textos de filósofos franceses (por exemplo, os de Lacan, Derrida, Deleuze, etc.), Alice Jardine afirma que,

\footnotetext{
9 Por limitações de espaço, na abordagem aqui proposta decidi não entrar nas discussões da constituição do sujeito tratadas mais especificamente pela psicanálise e pela análise do discurso (por exemplo, por Pêcheux e Benveniste, $e$ por Kristeva e sua noção do sujet em procès). Para essas discussões, ver CosTA, Claudia de Lima. Off-Center: On the Limits of Theory and Lived Experience. Michigan, UMI, 1998, pp.42-108. Quanto às críticas feministas das abordagens psicanalíticas de Freud e Lacan a partir da tematização das várias categorias da diferença (gênero, raça, etnia, etc.) na construção do sujeito, ver ABEL, Elizabeth, Christian, Barbara, and Moglen, Helene. (eds.) Female Subjects in Black and White: Race, Psychoanalysis, Feminism. Berkeley, University of California Press, 1997; MANSFIELD, Nick. Subjectivity: Theories of the Self from Freud to Haraway. New York, New York University Press, 2000; e Grosz, Elizabeth. Jacques Lacan: A Feminist Introduction. London, Routledge, 1990.

${ }^{10}$ JARDINE, Alice. Gynesis: Figurations of Woman and Modernity. Ithaca, Cornell University Press, 1988, p.184.
} 
O sujeito no feminismo

para Derrida, a questão sobre como as mulheres poderiam ter acesso à subjetividade, escrever textos duradouros ou adquirir uma assinatura própria são perguntas incorretas perguntas eminentemente falogocêntricas. Ao invés disso, é a mulher que deve ser libertada de sua escravidão metafísica, e é a escrita que, como "operação feminina", pode e deve subverter a história dessa metafísica. Os atributos da escrita são os atributos da "mulher" - aquilo que perturba o Sujeito, a Dialética e a Verdade é feminino em sua essência. (...) Mulher é sempre, segundo Derrida, aquilo que desafia o homem, o que o questiona. ${ }^{11}$

De acordo com Teresa de Lauretis, quando os pósestruturalistas franceses percebem a feminilidade como uma figura puramente textual (Derrida), como um corpo de prazeres difusos (Foucault), como superfícies de investimentos libidinosos (Lyotard), ou como um lugar-corpo de afetividade nãodiferenciada e, portanto, livre tanto da auto-representação como de repressões identitárias (Deleuze), eles não estão fazendo nada mais do que simplesmente "situando novamente a subjetividade feminina no sujeito masculino". ${ }^{12}$ Para Lauretis,

somente através da negação da diferença sexual e de gênero como componentes da subjetividade de mulheres concretas - portanto, através da negação da história da opressão e resistência política das mulheres $e$ da contribuição epistemológica do feminismo para a redefinição da subjetividade e sociabilidade - é que os filósofos podem ver nas "mulheres" o repositório privilegiado do "futuro da humanidade". ${ }^{13}$

\footnotetext{
${ }^{11}$ ID., IB., p.183.

${ }^{12}$ Lauretis, Teresa de. Technologies of Gender: Essays on Theory, Film, and Fiction. Bloomington, Indiana University Press, 1987, pp.23-4.

${ }^{13}$ ID., IB., p.24.
} 
Um argumento semelhante é feito por Probyn em sua influente discussão sobre os "homens no feminismo", quando nos lembra que um dos efeitos mais devastadores desses usos do feminino, apesar dos aparentemente bem intencionados teóricos franceses, acabou sendo novamente a reinscrição da mulher como o Outro. ${ }^{14}$ Dadas as conotações históricas do feminino ("até que ponto podemos falar de 'mulher' sem nos referirmos ao feminino biológico?" ${ }^{15}$, seu uso não minou

as bases sobre as quais os homens têm historicamente falado. A figura do feminino silencia as mulheres e dá aos homens ainda mais para dizer e um lugar confortável de onde falar. [Além disso, a figura do feminino não capacitou] as feministas no sentido de articular experiências históricas $e$ materiais das mulheres como pontos de partida discursivos. ${ }^{16}$

\footnotetext{
${ }^{14}$ Probyn, E. Sexing the Self... Op.cit., pp.32-57. Apesar das apropriações masculinas do feminino com intenção de reinscrever o sujeito masculino em um modo universalista que exclui as mulheres, dispensar completamente essas contribuições teóricas seria como jogar fora o bebê com a água do banho. A utilidade para o feminismo da desconstrução, por exemplo, não pode ser subestimada. Segundo Leslie Rabine, várias feministas têm usado conceitos e estratégias da desconstrução para abordar tópicos referentes à identidade de gênero, à escrita, ao essencialismo e à crítica de oposições binárias tais como masculino/feminino, entre outras questões. O que preocupa as feministas, conforme Rabine ressalta na análise que faz do trabalho de Chodorow como exemplo de prática desconstrucionista, é que nas instituições acadêmicas dos Estados Unidos, onde tanto os insights teóricos encontrados na desconstrução como outras teorias pós-estruturalistas desenvolvidas por homens são extremamente valorizados, aquelas "descobertas paralelas desenvolvidas na teoria feminista que se baseiam em um código diferente e, o que é mais pertinente, que são produzidas por mulheres, passam desapercebidas ou desconhecidas". RABINE, Leslie. A Feminist Politics of Non-Identity. Feminist Studies, 14(1), 1988, p.17.

${ }^{15}$ JARDINE, A. Gynesis... Op.cit., p.43.

${ }^{16}$ Probyn, E. Sexing the Self... Op.cit., p.51.
} 
O sujeito no feminismo

Outras feministas, em uma direção teórica radicalmente oposta - embora informadas por princípios pós-estruturalistas semelhantes - têm lutado pelo estabelecimento e validação da categoria "mulher" tanto como sujeito quanto signo. Ao fazer isso, elas argumentam que não estão construindo mais outra subjetividade essencial simplesmente porque, no patriarcado, nunca foi permitido à "mulher" a condição de sujeito. Portanto, como Smith e outros colocam com perspicácia, apelos à positividade da identidade "mulher" já são uma forma de transgressão. Além disso, tais reivindicações também resultam em uma contradição, pois a posição da "mulher" como sujeito - dado que ela só poder ser representada dentro da economia simbólica dominante - já foi definida pelo patriarcado como o lugar do "outro". Em outras palavras, ela é "irrepresentável, a não ser como representação", existindo em um constante deslizar entre "mulher" como signo e mulheres como sujeitos de "relações reais" ${ }^{17}$ Aqui reside a dupla visão do feminismo: seu sujeito, longe de ser apenas uma metáfora ou uma questão de pura diferença, existe dentro $e$ fora da ideologia de gênero, em um espaço que, usando terminologia cinematográfica, Lauretis define como spaceoff. Isso não quer dizer que tal sujeito exista fora dos discursos e das representações, como no mundo "real"; ao contrário, tomando de empréstimo o exemplo do enquadramento cinematográfico, "esse espaço, embora não visível, pode ser inferido a partir daquilo que o enquadramento deixa visível", existindo paralelamente a esse. ${ }^{18}$

Defendo que o movimento para dentro e para fora das representações/discursos não gera negatividade, mas, ao contrário, uma positividade que também fala dos investimentos particulares do sujeito (materiais, emocionais, libidinosos) em posições discursivas a partir das quais se experiencia o mundo. Resumindo meu argumento, a vitalidade atribuída à teoria

${ }^{17}$ LAURETIS, T. Technologies of Gender... Op.cit., p.20 e 10.

${ }^{18}$ ID., IB., p.26. 
feminista hoje vem da sua posição dentro dos discursos tanto autorizados quanto exteriores ou mesmo excessivos a eles próprios, ou seja, da posição da "mulher" como essencial e também como radicalmente "outra". O reconhecimento desse fato - um insight obtido através de práticas pessoais e da micropolítica da vida cotidiana das mulheres - concede ao sujeito uma perspectiva "ex/cêntrica", menos pura, menos unificada e a qual percebe a identidade como um lugar de posições múltiplas $e$ variáveis dentro do campo social, ao mesmo tempo que entende a experiência como o "resultado de um conjunto complexo de determinações e lutas, um processo de renegociações contínuas das pressões externas e resistências internas". ${ }^{19}$

Como sugiro em seguida, fundamentando sua análise nas práticas cotidianas das mulheres e nas resistências dessas em relação às especificidades históricas, o feminismo foi capaz de recorrer à categoria "mulher" sem retornar a uma posição nominalista. ${ }^{20} \mathrm{~A}$ fabricação de uma identidade de gênero fixa ("o essencialismo estratégico" ou uma "idealização mínima", segundo Gayatri Spivak) ${ }^{21}$ continua sendo um momento crucial - embora insuficiente, problemático e contestado - de um projeto feminista mais amplo. Tão logo o sujeito é cristalizado em uma posição, ele/a é questionado/a pelas próprias exigências do campo social dentro do qual está situado/a. A insistência quanto a uma especificidade feminina, de acordo com Naomi Schor, continua sendo uma tática contra a dissipação da mulher dentro de uma (in)diferença efetuada por alguns teóricos pós-estruturalistas. ${ }^{22}$

\footnotetext{
${ }^{19}$ ID. Eccentric Subjects: Feminist Theory and Historical Consciousness. Feminist Studies 16(1), 1990, p.137.

20 "Nominalismo" aqui se refere à visão que define a categoria "mulher" como uma ficção, sendo a tarefa da crítica feminista desvelar tal ficção.

${ }^{21}$ SPIVAK, Gayatri C. Interview with Angela McRobbie. Block (10), 1985, pp.5-9.

${ }^{22}$ SCHOR, Naomi. Dreaming Dissymmetry: Barthes, Foucault, and Sexual Difference. In: WeED, Elizabeth. (ed.) Coming to Terms: Feminism, Theory, Politics. New York, Routledge, 1989, pp.47-58.
} 
O sujeito no feminismo

De fato, essa estratégia também constitui uma condição de possibilidade para o feminismo, transformando-o em um dos empreendimentos teóricos e políticos mais incisivos e de mais profundo impacto entre as lutas contemporâneas contra a sujeição, a opressão e a dominação. Como não podemos discorrer sobre o sujeito no feminismo sem abordarmos seus corolários teóricos, passo agora à análise de algumas questões que circundam o essencialismo $e$ o antiessencialismo e que estão implícitas nas várias posições a favor e contra o uso dos signos identitários.

\section{O feminismo e a política da identidade}

Uma forma de colocar a questão da identidade em relação ao sujeito do feminismo seria explorar a controvérsia referente ao essencialismo e seus cognatos versus o antiessencialismo. Depois da disputa pós-estruturalista no que tange às noções de sujeito $e$ ao solapamento das categorias identitárias levado a cabo pela desconstrução, feministas de algumas tendências teóricopolíticas, temerosas em relação aos perigos dos apelos essencialistas, desautorizaram qualquer referência ao termo "mulher", independentemente do caráter provisional dessa categoria. Segundo Linda Alcoff, a tentativa de fundamentar a política feminista na "mulher" foi considerada "politicamente reacionária e equivocada em termos ontológicos", já que, no fim das contas, ela se apoiava em uma concepção humanista do sujeito feminino, centrada, unificada e autêntica, amarrada a sua identidade essencial como mulher. ${ }^{23} \mathrm{Na}$ visão de várias feministas pós-estruturalistas, a forma encontrada para escapar das armadilhas do pensamento essencialista consistiu na afirmação da diferença total através de uma prática feminista negativa ancorada nos preceitos da desconstrução. A "mulher" foi concebida como

${ }^{23}$ AlCOFF, Linda. Cultural Feminism versus Poststructuralism: The Identity Crisis in Feminist Theory. Signs 13(3), 1988, p.407. 
"o que não pode ser (...) algo que nem pertence à ordem dos seres", uma categoria vazia, uma ficção, uma identidade que não poderia ser determinada ou assegurada. ${ }^{24} \mathrm{Em}$ outras palavras, "mulher" tornava-se uma construção discursiva que sustentava as relações opressivas de poder. Levado às últimas conseqüências, tal ceticismo nominalista acabou celebrando um "feminismo sem mulheres". Diante de tal feminismo, Alcoff pergunta:

$\mathrm{O}$ que podemos exigir em nome das mulheres se "mulheres" não existem e as exigências em seu nome simplesmente reforçam o mito de que elas existem? De que forma podemos falar abertamente contra o sexismo como sendo prejudicial aos interesses das mulheres se tal categoria é uma ficção? Como podemos exigir o aborto legal, creches adequadas ou salários compatíveis sem que se invoque um conceito de "mulher"?25

Tania Modleski, cautelosa no que ela interpreta como um novo apagamento dos sujeitos femininos induzido pelos homens, declara um "postmortem do pós-feminismo" e estabelece para si própria a tarefa de resgatar as mulheres para o feminismo ${ }^{26}$ De acordo com a autora,

é fácil perceber porque as teorias pós-estruturalistas têm atraído as feministas. Como o feminismo tem grande interesse na visão forjada por Simone de Beauvoir de que não nascemos, mas nos tornamos "mulher"(porque se isso não fosse verdade seria difícil imaginar qualquer mudança social), pensadores como Lacan e Foucault forneceram

\footnotetext{
${ }^{24}$ KRISTEVA, Julia. Woman Can Never Be Defined. In: MARKS, Elaine and DE Courtivron, Isabelle. (eds.) New French Feminisms. New York, Schocken, 1981, p.137.

${ }^{25}$ AlCoff, L. Cultural Feminism... Op.cit., p.420.

${ }^{26}$ Sugestivamente, o livro de Tania Modleski, intitulado Feminism Without Women: Culture and Criticism in a "Postfeminist" Age (New York, Routledge, 1991), é dedicado "às mulheres".
} 
O sujeito no feminismo

ferramentas de análise com as quais podemos começar a árdua tarefa de desvelar esse "tornarmos mulheres". Entretanto, conforme as feministas argumentam cada vez mais, a proposição outrora animadora, que defendia a nãoexistência de uma natureza feminina "essencial", foi a tal ponto refinada que é agora freqüentemente utilizada para coibir as próprias mulheres de fazer quaisquer generalizações sobre, ou exigências políticas a favor de, um grupo chamado "mulheres". ${ }^{27}$

Além disso, críticas da política baseada em conceitos identitários (as que se conclamam antiessencialistas) afirmam que tais conceitos já demonstraram extrema instabilidade, fragilidade e vulnerabilidade na sustentação de qualquer tipo de projeto político de emancipação. Argumenta-se que uma política da identidade tende a compartimentar e objetivar o caráter diversificado $e$ contraditório da experiência vivida dentro de categorias identitárias, tais como raça, gênero e sexualidade. De acordo com Barbara Epstein,

essa política também faz com que seja mais difícil para as pessoas entender sua própria experiência de forma complexa, compreender que diferentes aspectos da identidade podem assumir significados diversificados em momentos diferentes, ou que esses possam ser mais ou menos importantes em fases diversas de suas vidas. ${ }^{28}$

O problema das críticas acima abordadas é que, embora pertinentes, são, de certa forma, mal direcionadas. Seu alvo é o nominalismo indefensável (e uma visão monolítica e estática de identidade), ao qual poucas das assim chamadas feministas pósestruturalistas gostariam de se subscrever. As questões são mais sutis do que a forma como foram representadas nos debates

${ }^{27}$ ID., IB., p.15 (ênfase no original).

${ }^{28}$ EPSTEIN, Barbara. "Political Correctness" and Collective Powerlessness. Socialist Review 21(3-4), 1991, pp.25-26. 
relativos ao essencialismo e à política da identidade. Deveria ser relembrado aqui que desafiar a coerência e a unidade da "mulher", ou o poder explanatório dessa categoria - até mesmo afirmar que ela é, em princípio, uma categoria vazia ou uma ficção -, não nos faz cúmplices de um "feminismo ginocida" (mesmo Modleski, que cunhou tal termo, se dispõe a fazer várias concessões ao antiessencialismo). O que está simplesmente sendo colocado é, em primeiro lugar, que a "mulher" é uma categoria histórica e heterogeneamente construída dentro de uma ampla gama de práticas e discursos, e sobre as quais o movimento das mulheres se fundamenta (conforme Ellen Rooney sugere, análises e políticas feministas não podem estar engajadas a menos que se assuma uma posição "como mulher"). ${ }^{29}$ Dado o contexto conjuntural que acompanha certas exigências políticas, essa categoria é (e deveria continuar sendo) utilizada para articular as mulheres politicamente, reconhecendo-se, contudo, suas temporalidades e densidades divergentes. De acordo com Denise Riley,

\begin{abstract}
A categoria "mulheres" é histórica e discursivamente construída, sempre em relação a outras categorias que também se modificam; "mulheres" é uma coletividade volátil na qual os seres femininos podem estar posicionados de formas bastante diferentes, de modo que não se pode confiar na aparente continuidade do sujeito "mulheres"; "mulheres", como coletividade, é uma categoria sincrônica e diacronicamente errante, enquanto que, a nível individual, "ser mulher" também é algo inconstante, que não consegue oferecer uma base ontológica. Ainda assim, deve ser destacado que essas instabilidades da categoria são o sine qua non do feminismo, que de outra forma se
\end{abstract}

${ }^{29}$ ROONEy, Ellen. Commentary. In: WEED, Elizabeth. (ed.) Coming to Terms... Op.cit., pp.230-239. 
O sujeito no feminismo

perderia por um objeto, ficando despojado de lutas e, em resumo, sem muita vida. ${ }^{30}$

Portanto, segundo Riley, reconhecer a instabilidade semântica da categoria "mulheres"

não faz necessariamente com que mergulhemos no vago redemoinho dos seres "pós-gendrados", abandonando as posições críticas do feminismo (...), passando a celebrar um carnaval de sexualidades difusas e contingentes ${ }^{31}$;

Ao invés disso, tal reconhecimento nos posiciona nas regiões de formações histórico-discursivas, onde a história de uma categoria deve ser compreendida à luz da história de várias outras categorias (classe, raça, etnia, sexualidade, nação, entre outras).

Um segundo aspecto a ser ressaltado é o de que afirmar que identidades são ficções ou efeitos da linguagem (como os desconstrucionistas adoram fazer) não deveria levar ninguém a repudiar reivindicações identitárias, posto que desabilitariam qualquer ação política. Ao contrário, essa afirmação permite uma política mais transformadora, já que conceber identidades como desagregadoras e instáveis seria como "lutar contra a tendência de apagar diferenças e inconsistências para a produção de sujeitos políticos estáveis". ${ }^{32}$

Em antológica entrevista com Angela McRobbie, Spivak se refere às invocações públicas da "mulher" como "essencialismo positivo", uma posição que as feministas devem arriscar, embora "conscientes quanto aos limites do (auto)posicionamento

${ }^{30}$ RILEY, Denise. Am I That Name? Feminism and the Category of "Women" in History. Minneapolis, University of Minnesota Press, 1988, p.2.

${ }^{31}$ ID., IB., p.5.

${ }^{32}$ Fuss, Diane. Essentially Speaking: Feminism, Nature, and Difference. New York, Routledge, 1989, p.104 
Claudia de Lima Costa

\section{- individual e coletivo" - de forma que este possa ser estrategicamente efetivo. ${ }^{33}$ Conforme ela salienta,}

isso nos oferece uma percepção mais prática do pósestruturalismo do que aquele tipo de metafísica negativa sempre nervosa com a possibilidade do essencialismo estar de tocaia pelos cantos. ${ }^{34}$

${ }^{33}$ SpIVAK, G. Interview with Angela McRobbie. Op.cit., pp.5-9.

${ }^{34}$ ID., IB., pp.7-8. Em outra entrevista, ao tratar do problema de o essencialismo estratégico se tornar uma armadilha - ou seja, minimizando a diferença entre o essencialismo positivo e o substantivo -, Spivak alerta para o fato de que a estratégia só funciona através de persistente crítica ou vigilância; "de outra forma [a estratégia] ficaria congelada como algo que se chama posição essencialista" (SPIVAK, G. "In a Word". Interview. Differences 1(1), 1989, p.127). Expressando preocupação quanto ao modo pelo qual suas reivindicações em relação ao essencialismo estratégico ficaram contidas dentro do que ela chama de "cultura personalista", como as das instituições acadêmicas dos Estados Unidos, a autora reconsidera sua posição, advertindo que seu interesse agora "como professora $e$, de certa forma, como ativista é pela 'construção para a diferença' (build for difference), em outras palavras, significa pensar sobre o que se poderia estar fazendo ou dizendo estrategicamente, às vezes taticamente, dentro de uma estrutura institucional bastante poderosa. Dada a forma de funcionamento dessas coisas - a colaboração entre técnicas de conhecimento e estratégias de poder $-e$ devido a estarmos onde estamos, meu projeto é o de tomar conhecimento do fato de que, apesar da minha benevolência pessoal, essas coisas são usadas como se fossem teorias. E por isso devemos ter cuidado para que elas não falhem" (p.128). Mencionando Derrida, Spivak lembra àqueles que adotaram a posição antiessencialista que "a crítica da essência à la desconstrução procede em termos da utilidade inevitável de algo que é sumamente perigoso. (...) A crítica ao essencialismo não deveria ser vista como crítica no sentido coloquial, anglo-americano, de se ter inclinações contrárias, mas como uma crítica no forte sentido filosófico europeu, ou seja, como um reconhecimento da utilidade daquilo que se critica" (pp.29-30). Judith Butler, criticando Spivak, escolhe o conceito de "posicionalidade estratégica" ao invés de "essencialismo estratégico" a fim de alertar sobre os perigos políticos do uso dos signos identitários (BUTLER, Judith. Bodies That Matter: On the Discursive Limits of Sex. New York, Routledge, 1993). De acordo com ela, "ao admitir a provisionalidade estratégica do signo (ao invés de seu essencialismo estratégico), tal identidade pode se tornar um lugar de contestação e revisão, assumindo, na verdade, um conjunto futuro de significados que aquelas de nós que fazem uso dele no momento presente 
O sujeito no feminismo

Ecoando a preocupação de Spivak, Elizabeth Grosz sustenta que, se vamos ou não "usar" o essencialismo, isso dependerá de "avaliações políticas cuidadosas, e não de certezas evidentes". 35

Diane Fuss, em sua abrangente e contundente discussão sobre o essencialismo, adverte que, já que "essência" é um conceito escorregadio, contingente e mutável (não é monoliticamente codificado), seu uso como estratégia politicamente progressista ou conservadora dependerá fundamentalmente não de qualquer valor intrínseco associado ao signo, mas, sim, "das relações discursivas mutáveis e determinantes que o produziram" - ou seja, no "quem o está utilizando, como está sendo utilizado e onde seus efeitos estão concentrados". ${ }^{36}$ Em outras palavras, impugnar qualquer uso do essencialismo como inerentemente reacionário é "agir com se o essencialismo tivesse uma essência". ${ }^{37}$

Adotando uma postura semelhante à de Spivak a respeito do essencialismo estratégico, Chantal Mouffe coloca que a história da identificação do sujeito caracteriza-se basicamente por um

talvez nem possamos prever" (p.19). Um problema que eu vejo na crítica ao essencialismo de Butler é que ela concebe as categorias identitárias como extremamente fixas e monolíticas, em oposição às identidades fluidas $e$ permeáveis presentes, por exemplo, nos textos de grande número de feministas de diferentes raças, etnias, orientações sexuais, nacionalidades, etc. - em resumo, de diferentes hibridismos. Para uma discussão desses textos, ver CosTA, Claudia de Lima. (org.) Travessia: Revista de Literatura (29/30), 1997 (número especial sobre "Gêneros ex/cêntricos: literatura fora-da-lei").

${ }^{35}$ Grosz, Elizabeth. Space, Time, and Perversion: Essays on the Politics of Bodies. New York, Routledge, 1995, p.57. Essa autora reconfigura o paradoxo da "mulher" - identificado tanto por Lauretis como por Alcoff - em termos de um conflito feminista entre os objetivos do rigor intelectual (antiessentilismo) versus os objetivos das lutas políticas feministas contra a opressão (essencialismo estratégico). Recusando-se a aceitar tais escolhas como as únicas disponíveis, Grosz propõe uma reformulação do vínculo tradicional entre teoria e prática política "de forma que os critérios de avaliação intelectual sejam mais "politizados' e os objetivos da luta política, mais 'teorizados"” (p.56).

${ }^{36}$ Fuss, D. Essencially Speaking... Op.cit., p.20 (ênfase no original).

${ }^{37}$ ID., IB., p.21. 
duplo movimento. O primeiro se refere ao descentramento do sujeito a fim de expor sua não-fixidez essencial (conforme discuto no início deste artigo); o segundo movimento consiste na "instituição de pontos nodais, fixações parciais que limitam o fluxo do significado sob o significante" ${ }^{38}$ Esse segundo momento é alcançado através de práticas históricas, políticas e contingentes de articulação entre as várias posições que o sujeito ocupa de forma a gerar o que Mouffe chama de "efeitos totalizantes":

Embora não exista um vínculo necessário entre as diferentes posições de sujeito, no campo da política há discursos que tratam de promover a articulação entre elas desde diferentes pontos de partida. É por isso que cada posição de sujeito se constitui dentro de uma estrutura discursiva essencialmente instável, posto que se submete a uma variedade de práticas de articulação que constantemente a subvertem $e$ transformam. Por isso não há nenhuma posição de sujeito cujos vínculos com outras estejam assegurados de maneira definitiva e, portanto, não há identidade social que possa ser completa $e$ permanentemente adquirida. Isto não significa, no entanto, que não possamos reter noções como "classe trabalhadora", "homens", "mulheres", "negros" ou outros significantes que se referem a sujeitos coletivos. Não obstante, uma vez que tenha sido descartada a existência de uma essência comum, seu status deve ser concebido em termos do que Wittgenstein designa como "semelhanças familiares", e sua unidade deve ser vista como o resultado de uma fixação parcial de identidades mediante a criação de pontos nodais. ${ }^{39}$

\footnotetext{
${ }^{38}$ MoufFe, Chantal. Feminismo, cidadania e política democrática radical. Debate Feminista (edição especial "Cidadania e feminismo"), 1999, p.31.

${ }^{39}$ ID., IB., p.34. Para uma discussão muito esclarecedora do essencialismo e da noção de "semelhanças familiares" de Wittgenstein quando aplicadas aos conceitos centrais da crítica feminista - gênero e mulher - ver NiCHOLSON, Linda. Interpretando o gênero. Revista Estudos Feministas 8(2), 2000, p.9-42.
} 
O sujeito no feminismo

Acredito que essa dupla controvérsia quanto à categoria "mulher" cria um falso dilema: ou dispomos de uma unidade preestabelecida na figura da "mulher" ou não pode haver base alguma para a política feminista. O que passa despercebido, segundo Mouffe, é que a negação da primeira alternativa não impede a construção de formas múltiplas de unidade e de ação comum. Deixando de lado as bandeiras essencialistas $e$ antiessencialistas, a construção de pontos nodais $e$ as fixações parciais permitem o estabelecimento de formas de identificação em torno da categoria "mulher". Talvez deveríamos assumir o que pode ser chamado de uma posição antiessencialista essencialista (jogando um termo contra o outro a fim de anulá-los), já que "mulher", como Lauretis nos sugere, permanece até hoje "mais como um projeto (...) do que como uma descrição da realidade existente". ${ }^{40}$ Para Alcoff, uma saída dos impasses teóricos até aqui expostos seria definir "mulher como posicionalidade", em que posição se refere a uma identidade politicamente assumida, que está invariavelmente ligada à localização do sujeito (seja ela social, cultural, geográfica, econômica, sexual e assim por diante) e a partir da qual interpretamos o mundo e na qual nos fundamentamos. ${ }^{41}$ De acordo com a autora,

se associarmos o conceito de política da identidade com um conceito de sujeito como posicionalidade, podemos conceber o sujeito como não-essencializado, resultado de uma experiência histórica, e ainda assim manter nossa capacidade política no sentido de tomar o gênero como um importante ponto de partida. Dessa forma, podemos dizer que o gênero não é natural, biológico, universal, a-histórico ou essencial e ainda assim defender que ele é relevante, já

\footnotetext{
${ }^{40}$ LAuRETIS, Teresa de. The Essence of the Triangle or, Taking the Risk of Essentialism Seriously: Feminist Theory in Italy, the U. S., and Britain. Differences 1(1), 1989, p.5.

${ }^{41}$ AlCOFf, L. Cultural Feminism... Op.cit.
} 
Claudia de Lima Costa

que o estamos assumindo como uma posição a partir da qual podemos agir politicamente. ${ }^{42}$

Alcoff destaca dois pontos que se referem ao conceito de mulher como posicionalidade. Primeiro, esse é um termo relacional; segundo, e talvez mais importante, as diferentes posições, intersectadas por outras categorias sociais e ocupadas pelas mulheres, podem ser usadas como um lugar a partir do qual essas mulheres se engajam com a construção, e não com a simples descoberta dos significados. É nesse sentido que o conceito de posicionalidade evita a traiçoeira rede do essencialismo. Além disso, ele permite que outras identidades sociais e relações além do gênero possam assumir prioridade na formação da consciência multivocal das mulheres. ${ }^{43}$

${ }^{42}$ ID., IB., p.433. Baseada nos trabalhos de Riley e de Lauretis, Alcoff percebe a "experiência" como uma categoria crucial através da qual se pode compreender a produção dos sujeitos gendrados. Essa categoria permite que se desessencialize o gênero, já que esse não se torna "um ponto de partida já dado, mas sim um pressuposto ou construção que se pode formalizar de forma não-arbitrária, através de uma matriz de hábitos, práticas e discursos. Além disso, o gênero é uma interpretação da nossa história dentro de uma constelação discursiva específica - uma história na qual somos sujeitos da construção social e estamos a ela sujeitados" (p.431). Caren Kaplan, por outro lado, critica Alcoff por não conseguir apresentar saída para o conceito estático de identidade. De acordo com ela, Alcoff, embora engajada na crítica da identidade e da metafísica da presença, oferece em troca um conceito muito rígido e singular de posicionalidade que, no final das contas, abala a força desconstrucionista do seu argumento. KAPLAN, Caren. Questions of Travel: Postmodern Discourses of Displacement. Durham, Duke University Press, 1996.

${ }^{43}$ Como Norma Alarcón enfatiza na sua crítica à epistemologia da perspectiva de gênero apresentada por Lauretis (a qual defende que o sujeito feminino é sempre construído e definido no gênero, a partir do gênero), um foco exclusivo no gênero como categoria unificadora de todas as mulheres $e$ formadora de suas consciências "impede 'a busca por solidariedade' através de formações políticas diferentes e da exploração de teorias alternativas do sujeito da consciência". ALARCón, Norma. The Theoretical Subject(s) of This Bridge Called My Back and Anglo-American Feminism. In: AnZALDÚA, Gloria. (ed.) Making Face, Making Soul/Haciendo Caras. San Francisco, Aunt Lute Books, 1990, p.364. 
O sujeito no feminismo

Entretanto, feministas contrárias à política da identidade e às suas dificuldades epistemológicas defendem que nem sempre uma posição política é oferecida àqueles grupos que historicamente tiveram negado acesso à identidade ou à individualidade - ou que não dispunham de meios para tornar suas experiências visíveis. ${ }^{44}$ Tais grupos ainda permanecem fora da política, desautorizados, "já que ser oprimido/a significa estar impossibilitado/a não apenas de assumir uma identidade, mas também de reivindicá-la". ${ }^{45}$ Uma resposta possível a essas ressalvas seria repensar a identidade como aquilo do qual se parte (para chegar a outro lugar), isto é, como uma estratégia política pessoal e/ou coletiva de sobrevivência, independentemente de quão múltipla, fluída $e$ contraditória a estratégia possa ser. A identidade, assim concebida, passa a ser algo pelo qual se deve lutar constantemente, e não simplesmente algo que nos é concedido na construção de alianças e contigüidades transpessoais.

Tendo dito isso, na próxima seção direciono minha discussão para debates sobre a forma como identidades podem ser positivamente produzidas nas margens, nos space-off e nos interstícios das estruturas e dos discursos dominantes. Além de salientar temas relacionados à questão do lugar de enunciação (isto é, os lugares geo-políticos, semióticos, somáticos e psíquicos que o sujeito ocupa) - um determinante central na topografia do sujeito -, gostaria de enfatizar que estar (des)locado nas

\footnotetext{
${ }^{44}$ Laura Downs, na sua exposição das várias dificuldades epistemológicas da política da identidade, além das anteriormente mencionadas, defende que o conhecimento baseado em uma noção restrita de identidade se apóia na suposição de que "a identidade do indivíduo é coincidente com sua identidade corporal", postergando assim a possibilidade de se conhecer através de fronteiras corporais (Downs, Laura. If "Woman" Is Just an Empty Category, Then Why Am I Afraid to Walk Alone at Night? Identity Politics Meets the Postmodern Subject. Comparative Studies in Society and History 35(2), 1993, p.417). Para um estimulante debate sobre corporalidade e identidade, ver MALUF, Sonia W. Corporalidade e desejo: Tudo sobre minha mãe e o gênero na margem. Revista Estudos Feministas, 10(1), 2002, p.143-153.

${ }^{45}$ Alarcón, N. The Theoretical Subject(s)... Op.cit., p.364.
} 
Claudia de Lima Costa

margens exige do sujeito o solapamento de várias categorias epistemológicas, tais como lar, comunidade, linguagem comum, entre outras, de forma que a identidade e a política da diferença possam ser concatenadas.

\section{Subjetividades ex/cêntricas e a busca de uma política da diferença}

Na literatura feminista produzida por sujeitos situados nas várias margens das narrativas ocidentais dominantes, há uma profusão de relatos de vida e outras formas de autobiografia $e$ testemunhos que tematizam tanto a construção de sujeitos quanto a de um sentido de pertencimento a partir dos múltiplos freqüentemente contraditórios e conflitantes - posicionamentos desses sujeitos dentro das estruturas de opressão. Já que o campo do poder se configura por meio de uma variedade de sistemas de diferença, o debate sobre identidade invariavelmente nos leva a controvérsias sobre o significado da diferença. A questão é como se pode conceituar a diferença - $e$, juntamente, as subjetividades/ identidades alternativas - de forma a evitar, por um lado, a armadilha do binarismo e, por outro, a sedução dos apelos pósmodernos à total fragmentação e dispersão. Para isso, certamente precisamos de uma teoria da diferença "cujas geometrias, paradigmas e lógicas estejam fora dos binarismos, das dialéticas e dos modelos de natureza/cultura de qualquer espécie" ${ }^{46}$

Ao discutir os debates feministas sobre a questão da diferença nos Estados Unidos desde o final da década de 1960 até os anos 1990, Nancy Fraser identifica três grandes transições teóricas: primeiro, temos uma noção da diferença apoiada exclusivamente na "diferença de gênero" (a qual apresenta um hiato radical entre mulheres e homens, defendendo a primazia da dominação de gênero) que, nos anos 1980, deu vazão a uma segunda e mais elaborada percepção das diferenças, não só

${ }^{46}$ HaRAWAY, Donna. Simians, Cyborgs, and Women: The Reinvention of Nature. New York, Routledge, 1991, p.129. 
O sujeito no feminismo

aquelas existentes entre homens e mulheres, mas também entre as mulheres (percepção esta que surgiu inicialmente entre as lésbicas, mulheres de cor e feministas do Terceiro Mundo residindo nos Estados Unidos e que articulava uma reposta à miopia geral do feminismo branco dominante) ${ }^{47}$ A terceira perspectiva apontada por Fraser, e que representa uma elaboração da anterior, enfatiza as "diferenças de intersecções múltiplas" entre e dentro das mulheres. ${ }^{48}$ Um dos principais fatores que contribuíram para essa última tendência foi o reconhecimento de que o campo social está intersectado por várias camadas de subordinação (tais como raça, etnia, classe, orientação sexual, idade, religião, nacionalidade, etc.) que não podem ser reduzidas unicamente à opressão de gênero. Essas camadas de subordinação ou eixos da diferença encontram-se mutuamente imbricados, onde cada categoria produz efeitos articulatórios sobre as outras em contextos históricos e geográficos específicos, viabilizando, assim, posições a serem ocupadas pelos sujeitos enquanto estabelecem agendas teóricas e políticas. Essa terceira abordagem, partindo da noção de interseccionalidade, expande significativamente o conceito de gênero, passando a formulá-lo como parte do conjunto heterogêneo de relações móveis, variáveis e transformadoras do campo social. ${ }^{49}$ Butler resume de forma competente essa visão da diferença afirmando que,

se alguém "é" mulher, isso não é tudo que tal sujeito é; o termo não é exaustivo, não porque uma "pessoa" pré-

\footnotetext{
${ }^{47}$ A antologia This Bridge Called My Back (MorAgA, Cherríe and AnZALDÚA, Gloria. [eds.] New York, Kitchen Table: Women of Color Press, 1981) marcou de forma contundente este segundo momento no debate feminista sobre a diferença.

${ }^{48}$ FRASER, Nancy. Equality, Difference, and Radical Democracy: The United States Feminist Debates Revisited. In: TREND, David. (ed.) Radical Democracy: Identity, Citizenship, and the State. New York, Routledge, 1996, pp.196-208.

${ }^{49}$ Para uma análise bastante aprofundada e ilustrativa das complexidades da intersecção entre gênero e raça, por exemplo, ver CRENSHAW, Kimberlé. Documento para o encontro de especialistas em aspectos da discriminação racial relativos ao gênero. Revista Estudos Feministas 10(1), 2002, pp.171-188.
} 
Claudia de Lima Costa

gendrada transcende uma parafernália específica do seu gênero, mas porque o gênero não é sempre constituído de forma coerente e consistente nos diferentes contextos históricos, e porque o gênero é intersectado por modalidades raciais, étnicas, sexuais, regionais e de classe das identidades discursivamente constituídas. Como resultado, torna-se impossível separar o "gênero" das intersecções políticas e culturais através das quais ele é invariavelmente produzido e mantido. ${ }^{50}$

A formulação de Butler sugere que, ao invés de dispormos uma categoria paralelamente às outras ao projetar cartografias do indivíduo, seria melhor se considerássemos uma intersecção muito movimentada, na qual vários vetores de diferença estão em constante sobreposição, deslocando uns aos outros, abrindo espaços intermediários (in-between spaces) ou interstícios nos quais o sujeito se posiciona, não importando quão provisoriamente. Contudo, em termos dos discursos da diferença, faz-se necessário enfatizar que esses interstícios não devem continuar sendo percebidos apenas como espaços ontológicos, abstrações desconstrucionistas ou sinais da Diferença pura. Sem dúvida, eles também são o produto, o material e os efeitos simbólicos de desequilíbrios históricos. ${ }^{51}$

Tal como para as teóricas feministas aqui abordadas (como, por exemplo, Lauretis e sua noção de sujeito excêntrico), para Homi Bhabha o sujeito que habita o mundo moderno do fin-de-

${ }^{50}$ BUTLER, Judith. Gender Trouble: Feminism and the Subvertion of Identity. New York, Routledge, 1990, p.3.

${ }^{51}$ Radhakrishnan corretamente nos lembra que "a desconstrução, ao aceitar a 'diferença pura', nega diferença aos ingredientes que constituem a 'Diferença' (...) Diferenças específicas, tais como a diferença feminista, a diferença étnica, do terceiro mundo e assim por diante, permanecem subentendidas, desmaterializadas e congeladas sob a dominação da Diferença”. RADHAKRISHNAN, R. Feminist Historiography and Post-Structuralist Thought. In: MEESE, Elizabeth and PARKER, Alice. (eds.) The Difference Within: Feminism and Critical Theory. Philadelphia, John Benjamins Publishing, 1989, p.193. 
O sujeito no feminismo

siècle sempre esteve "em excesso em relação à soma das 'partes' da diferença" ${ }^{52}$ Instigando seus/suas leitores/as a se afastarem das "singularidades da 'classe' ou do 'gênero' como categorias primordialmente conceituais e organizacionais", Bhabha nos convida a

pensar além das narrativas das subjetividades originárias e iniciais e enfocar aqueles momentos ou processos que são produzidos na articulação das diferenças culturais. Esses espaços in-between criam o terreno para a elaboração da individualidade - singular e grupal - que iniciam novos signos de identidade e lugares inovadores de colaboração e contestação, no ato de definir a própria idéia de sociedade. $^{53}$

Dessa forma, para que a teoria feminista consiga desembaraçar as articulações da diferença configuradoras dos interstícios, ela deve empregar uma heterogeneidade de métodos críticos que privilegiem "análises complexas, de engajamento múltiplo, porém com foco local" sobre a relação entre a subjetividade $e$ as matrizes da dominação/subordinação. ${ }^{54} \mathrm{~A}$ fim de conseguir isso, precisamos enfocar o conceito de lugar nas teorias feministas sobre identidade, diferença e subjetividade de modo que, como feministas, possamos nos tornar mais responsáveis em relação às coisas que dizemos e fazemos e aos lugares/posições a partir dos quais dizemos e fazemos tais coisas. Cartografar lugares, em especial aquelas zonas intermezzo de enunciação, fornecerá ao sujeito que teoriza as ferramentas necessárias para uma melhor apreensão dos "processos através

\footnotetext{
${ }^{52}$ BHABHA, Homi. The Location of Culture. New York, Routledge, 1994, p.2.

${ }^{53}$ ID., IB., pp.1-2.

${ }^{54}$ FrankenBerG, Ruth and MANI, Lata. Crosscurrents, Crosstalk: Race, "Postcoloniality" and the Politics of Location. Culture Critique 7(2), 1993, p.306.
} 
Claudia de Lima Costa

dos quais as diferenças são criadas, ao invés do reconhecimento e consolidação de identidades discretas e primordiais". ${ }^{55}$

\section{O sujeito ex/cêntrico, o lugar da teoria e a teoria do lugar}

O desafio de teorizar o surgimento dos interstícios ou dos espaços in-between, alojando identidades mais híbridas, reside em encontrar linguagens apropriadas ou tropos discursivos através dos quais se possa representar ou simbolizar as posicionalidades e experiências múltiplas, variáveis e conflitantes do sujeito (ex/cêntrico). Por exemplo, Bhabha usa o termo "terceiro espaço" ao se referir àquele lugar produtivo (ou situação limiar, evitando qualquer política de polaridade) onde os sujeitos produzem não suas identidades, mas suas identificações - indicando um "processo de identificação com e através de outro objeto, um objeto de alteridade, em um ponto onde (...) o sujeito é sempre ambivalente, devido à intervenção daquela alteridade" ${ }^{56}$

A importância de se prestar atenção à dupla questão do lugar e da elocução (já que ambas se aplicam aos sujeitos e às teorias) na articulação de identificações não é, no entanto, uma preocupação recente e exclusiva da teoria feminista. Ela faz parte de uma longa herança nas tradições hermenêuticas tanto nas humanidades quanto nas ciências sociais. Debates sobre a "localização" do conhecimento revelaram que os loci de enunciação, tanto do/a observador/a quanto do/a observado/a (sua inscrição cultural, política, de gênero, classe e raça, juntamente com certas normas disciplinares), assume um papel formativo na construção de qualquer conhecimento do real e do "outro". Walter Mignolo, na discussão sobre o discurso colonial e

${ }^{55}$ KaPLAN, C. Questions of Travel... Op.cit., p.185. Para uma crítica das noções tríplices de identidade como diferença, fragmentação e hibridez, e da elaboração de uma lógica alternativa de identidade (lógica da alteridade, produtividade $e$ espacialidade), ver GrossberG, L. Identity and Cultural Studies... Op.cit., pp.87-107.

${ }^{56}$ BHABHA, H. The Location of Culture. Op.cit., p.211. 
O sujeito no feminismo

pós-colonial, afirma que qualquer conhecimento deve ser reconhecido como um diálogo entre uma diversidade de loci de enunciação. Para ele "é tanto o que se diz (e a audiência envolvida) quanto o que é dito (e o mundo a que se refere) que preservam ou transformam a imagem do real construída por atos de fala ou elocuções prévias". ${ }^{57}$

Embora a controvérsia em torno da política do lugar possa ter se originado nos primeiros desacordos com respeito à interpretação de textos, sustento que é no âmbito da teorização feminista que a problematização do lugar - e, juntamente com isso, questões de teoria crítica, prática estética e consciência política - se tornou axiomática. Ela foi usada não somente para medir o alcance das categorias analíticas do feminismo, mas mais significativamente - para avaliar a capacidade política das mesmas, ou seja, estimar até que ponto tais categorias podem ou não intervir nas estruturas da desigualdade social. Nesse sentido, pode-se certamente estabelecer um paralelo entre a ênfase que a teoria feminista contemporânea dá ao lugar de enunciação do sujeito e a sua preferência pelo conjunturalismo, juntamente com suas análises complexas e localmente enfocadas, de forma a apreender a "relação efetiva, mas não determinante entre os sujeitos e suas histórias, uma relação que é complexa, mutável, embora não "livre". 58

${ }^{57}$ Mignolo, Walter. Colonial and Postcolonial Discourse: Cultural Critique or Academic Colonialism? Latin American Research Review 28(3), 1993, p.128. Para um aprofundamento dessas questões, ver também Mignolo, W. Local Histories/Global Designs: Coloniality, Subaltern Knowledges, and Border Thinking. Princeton, Princeton University Press, 2000; e LANDER, Edgardo. (org.) La colonialidad del saber: eurocentrismo y ciencias sociales. Perspectivas latinoamericanas. Buenos Aires, Clacso, 2000.

${ }^{58}$ FrANKENBERG, R. and MANI, L. Crosscurrents, Crosstalk... Op.cit., p.306. Para outras discussões sobre teoria de articulação e conjunturalismo, ver LACLAU, Ernesto and Mouffe, Chantal. Hegemony and Socialist Strategy. London, Verso, 1985; HALL, Stuart. "On Postmodernism and Articulation". Interview. Journal of Communication Inquiry 10(2), 1986, pp.45-60; e GROSSBERG, Lawrence. 
O apelo da escritora chicana Cherríe Moraga no sentido de que se "teorize na carne" representa, de forma bastante enfática, uma dentre tantas outras tentativas recentes que pretendem dar destaque a uma política do lugar a fim de evitar a euforia pósmoderna, pluralista e neo-relativista presente em algumas variedades de feminismo, bem como em algumas correntes high fashion da teoria cultural. O que falta na representação festiva que o pós-modernismo faz da heteroglossia radical é o fato de que, de saída, já estamos diferentemente situados em lugares de privilégio e de opressão, e que só podemos narrar qualquer coisa a partir dos nossos pontos de vista específicos (o que é aqui compreendido no seu sentido literal e metafórico, ou seja, tanto como um lugar geográfico específico quanto como uma localização imaginada, política e mental). Captar esse lugar/ posição/localização em todas as suas dimensões múltiplas exige a historicização e politização do espaço, de forma que a construção $e$ a institucionalização das nossas respectivas diferenças juntamente com as práticas políticas que as articulam - possam ser melhor compreendidas $e$, por que não, melhor vivenciadas em nível emocional.

Para resumir até aqui o argumento, poderia dizer que se aceitarmos, com Pêcheux, que o sujeito é sempre um interdiscurso, o produto dos efeitos das práticas discursivas que o atravessam no curso de sua história, então se torna imperativo nos referirmos às especificidades da história desse sujeito - suas lignes d'erreur - na elucidação do complexo dialogismo entre o sujeito $e$ seus múltiplos lugares de enunciação. Mesmo considerando que os códigos biográficos e identitários na nossa cultura colorem $e$ estruturam as narrativas do eu, sujeitos não são meras extensões de tais histórias, mas podem ser considerados/as "simultaneamente autores/as e personagens" ${ }^{59}$ Além disso, devido

Bringing It All Back Home: Essays on Cultural Studies. Durham, Duke University Press, 1997.

${ }^{59}$ BENHABIB, Seyla. Situating the Self: Gender, Community, and Postmodernism in the Contemporary West. New York, Routledge, 1992, p.214. 
O sujeito no feminismo

à intervenção dessas histórias pessoais nos processos de identificação - as quais deixam, para lembrar Gramsci, "traços sem um inventário" -, nenhuma correspondência simples entre um sujeito e seu lugar/(con)texto pode ser satisfatoriamente estabelecida. Pelo contrário, essa correspondência (ou mesmo não-correspondência) dependerá da forma como esses sujeitos interagem com as práticas discursivas, realizando leituras e contraleituras dos textos sociais a partir das suas diferentes localizações.

Nesse ponto, gostaria de fazer três observações referentes à noção do lugar/localização como uma categoria analítica e política. Em primeiro lugar, e primordialmente, o lugar não deveria ser compreendido como se estivesse ancorado exclusivamente na ontologia e na biologia (ser mulher não nos transforma necessariamente em "irmãs na luta"). Ao contrário, a consciência quanto ao lugar de enunciação surge do reconhecimento de que a experiência concreta se torna um momento teórico-crítico para estratégias que buscam interrogar categorias analíticas juntamente com seus usos hegemônicos. ${ }^{60}$ Assim como no caso do conceito de "experiência", a noção de lugar/localização não pode nem ser concretamente definida nem abstraída de sua materialidade. Conforme Grossberg, dentro do campo da subjetividade, nossa localização em posições específicas "autoriza e reprime nossas possibilidades de experiência, de representar aquelas experiências e de legitimar aquelas representações". ${ }^{61}$ Entretanto, apesar de toda sua concretude, o

${ }^{60}$ Sobre o problema de se evitar essencializar a experiência concreta, ver SCOTT, Joan. Experiência. In: SILVA, Alcione L., LAGO, Mara C. de Souza e RAMOS, Tânia R. O. (orgs.) Falas de gênero. Florianópolis, Editora Mulheres, 1999, pp.21-56; Probyn, E. Sexing the Self... Op.cit.; MOHANTY, Satya P. The Epistemic Status of Cultural Identity: On Beloved and the Postcolonial Condition. Cultural Critique 24, 1993, pp.41-80; e CosTA, Claudia de Lima. Being Here and Writing There: Gender and the Politics of Translation in a Brazilian Landscape. Signs 25(3), 2000, pp.727-760.

${ }^{61}$ GrossberG, L. Identity and Cultural Studies... Op.cit., p.99. 
lugar que alguém ocupa também é construído através de narrativas e desejos, devendo ser também apreendido como história - não simplesmente como um espaço previamente definido, contornado por fronteiras naturais que protegem a identidade legítima do sujeito.

Por exemplo, para bell hooks, o lar - aparentemente o espaço mais seguro de todos os espaços - nunca é uma experiência sem mediações, pois seu significado varia se nos situarmos como colonizadores/as ou colonizados/as. ${ }^{62}$ Além disso, com a descolonização a experiência do lar também muda. Portanto, o lar não é apenas um lugar mas localizações múltiplas de dispersão $e$ fragmentação, $e$ que às vezes jamais podem ser alcançadas. Ele pertence, como bell hooks complementa, àquelas ficções necessárias que fabricamos para construir um senso de pertencimento e para localizar nossas identidades. Michèle le Doeuf, filósofa feminista, ao argumentar que o espaço do lar está sempre mudando, escreve:

Eu nasci em toda parte, sob os céus agora estilhaçados dos gregos, dentro dos tamancos de uma fazendeira bretã, em um teatro elisabetano, na fome e privação de minha avó, e na escola secular, compulsória e livre que o Estado foi tão gentil em me oferecer, mas também nas rebeliões que foram só minhas, nas bofetadas que as seguiram ou precederam, na aflição lúcida de Simone de Beauvoir e no fogão de Descartes. E há mais por vir. ${ }^{63}$

Em segundo lugar, localizações (independentemente de quão locais ou diminutas) são inevitavelmente pontuadas $e$ cortadas por diferenças e tensões múltiplas, bem como por circuitos e fronteiras que excedem a lógica binária do poder. De

${ }^{62}$ HOOKS, bell. Yearning: Race, Gender and Cultural Politics. Boston, South End Press, 1990.

${ }^{63}$ Le Doeuf, Michèle. Hipparchia's Choice: An Essay Concerning Women, Philosophy, Etc. Oxford, Blackwell, 1991, p.172. 
O sujeito no feminismo

acordo com Arjun Appadurai, o estudo da relação entre o local e o global, por exemplo, exige um modelo que enfatize tanto as conexões como as disjunções - i.e., os interstícios - entre o movimento transnacional de pessoas, de tecnologias, bens culturais e do capital cada vez mais heteroglóssico, e que, ao mesmo tempo, leve em conta os diferentes efeitos que tais transformações podem assumir em vários níveis locais. ${ }^{64}$ Assim sendo, a especificidade do local nunca é singular, e sim múltipla, à medida que é construída por aquilo que é exterior a ela. Em outras palavras, o lugar passa a ser o efeito das inter-relações entre o local e os outros lugares além dele. Conseqüentemente, a localização do sujeito é sempre o resultado de vários processos de estranhamento, pois ela/ele geralmente ocupa mais de um lugar simultaneamente em um cruzar constante de várias fronteiras $e$ ordens (qualquer fronteira é também um lugar de regulamentações e imposições). Deveria ser acrescentado que esse movimento é político por definição. Na verdade, precisamos apenas pensar na distinção que Bhabha faz entre política e poética do lugar. $\mathrm{O}$ exílio (o lugar de deslocamento) e a fronteira são tropos discursivos poderosos que tentam dar significado à condição do sujeito pós-moderno: nômade, estrangeiro/a, excêntrico/a, deslocado/a, descentrado/a. ${ }^{65}$ No entanto, sob os movimentos trópicos - especialmente aqueles relativos às experiências de deslocamento - e nas entrelinhas dos discursos sobre o nomadismo, está a materialidade das condições de

${ }^{64}$ APPADURAI, Arjun. Disjuncture and Difference in the Global Cultural Economy. In: Modernity At Large: Cultural Dimensions of Globalization. Minneapolis, University of Minnesota Press, 1996, pp.27-47.

${ }^{65}$ Para um ensaio sumamente poético e politicamente contundente das identidades a partir do cruzamento de fronteiras geopolíticas, ver SHOHAT, Ella. A vinda para a América: reflexões sobre perda de cabelos e de memória. Revista Estudos Feministas 10(1), 2002, pp.99-117. Uma abordagem feminista do sujeito nômade pode também ser encontrada em BrAiDOTTI, Rosi. Nomad Subjects. Embodiment and Sexual Difference in Contemporary Feminist Theory. New York, Columbia University Press, 1994. 
desigualdade que erguem fronteiras em torno dos sujeitos, libertando alguns/algumas e excluindo outros/as. Kaplan oferece uma crítica afiada quanto ao uso de certas figurações do deslocamento - tais como o nômade, o imigrante, o cigano - em algumas teorias pós-modernas euro-americanas. Ela vê a figura do nômade como uma metáfora altamente carregada, apoiada em um modelo problemático de desterritorialização que não consegue escapar do discurso colonial (já que "desterritorialização é sempre uma reterritorialização, um aumento de território, uma imperialização". ${ }^{66}$ A autora ainda adverte que tornar-se menor, nômade, ou seja, "deixar de lado as identidades e práticas privilegiadas, exige a superação das formas e modos dos 'outros' da modernidade". ${ }^{67}$ Ainda assim, da mesma forma como todos os discursos imperialistas,

esses espaços e identidades são produzidos através da imaginação [de Deleuze e Guattari]; isto é, a produção de lugares de escape [dos excessos do capitalismo] ou de descolonização do colonizador indica um certo turismo teórico. ${ }^{68}$

A fronteira, ou "o terceiro espaço" de Bhabha e das teóricas feministas, portanto, deveria ser mais freqüentemente percebida como o resultado de lutas materiais (pobreza, racismo, homofobia, sexismo, etc.), e menos como uma conseqüência dos investimentos psíquicos ou da diferenciação infinita de significantes (que, no fim das contas, nos coloca em um lugar vazio). Assim, resistindo a uma noção exageradamente abstrata ou metaforizada de deslocamento, e a fim de restaurar "a força confrontadora da margem" ${ }^{6}$, precisamos desenvolver uma

${ }^{66}$ KaPLAN, C. Questions of Travel... Op.cit., p.89.

${ }^{67}$ ID., IB., p.88.

${ }^{68}$ ID., IB.

${ }^{69}$ RICHARD, Nelly. La condición centro-marginal post-moderna. Travessia: Revista de Literatura (29/30), 1997, p.58. 
O sujeito no feminismo

política da diferença para que o lugar possa ser recolocado no deslocamento. ${ }^{70}$ É através de uma política do lugar (e, conseqüentemente, uma política do posicionamento do sujeito) que as teorias feministas têm historicamente inscrito sua presença nos debates contemporâneos sobre fronteiras (geográficas, epistemológicas, sociais, econômicas, libidinosas, institucionais, lingüísticas e culturais), enquanto transgridem as discussões referentes à construção/desconstrução do sujeito. Se, como os seguidores de Derrida vêm apontando, o que é dito é um efeito do que não é dito - ou seja, do que foi apagado, do traço, para que algo possa ser dito -, isso (o que é dito) também é delimitado pelo lugar (e pelas ausências) de onde isso é dito. Quero afirmar, à guisa de conclusão, que essa é a difícil condição do feminismo.

A fim de evitar a indiferença em relação à diferença (no esboço de uma teoria e uma política da diferença), pensar sobre o lugar do sujeito na teoria se torna premente, já que tal reflexão poderá revelar os modos pelos quais esse sujeito (do feminismo) constrói novos loci de enunciação, proporcionando-lhe outras formas de ver e saber e, o que é mais importante, de aprender a partir da experiência daquelas que vivem em outros lugares.

${ }^{70}$ BAmmer, Angelica. Introduction. In: BAmmer,A. (ed.) Displacements: Cultural Identities in Question. Bloomington, Indiana University Press, 1994, p.xiv. 